\title{
CLAP HANDS, TRAINING PROFESSIONALS TO PROMOTE DISABLED PEOPLE LABOR INCLUSION IN ARTS AND CULTURE
}

\author{
Imma Miralles \\ Department of European Projects, Foro Técnico de Formación/Manager(Spain)
}

\begin{abstract}
Introduction: The CLAP HANDS “Creative Lab: Access to Profession for persons with Handicap" is a project financed by the ERASMUS+ Programme in 2 years (2017-2019), under the key action "Cooperation for Innovation and the Exchange of Good Practices".

Consortium: The project it has been coordinated by Institut Régional du Travail Social (IRTS) Languedoc-Roussillon- (FR) with 3 more partners from (FR), two from (ES), one from (PT) and one from (SE)

Objective: The main objective is to provide training to professionals who assist and work with people who have mental or physical disabilities, in order to contribute to their labor inclusion by developing their creativity and, on the other hand, to increase employer's awareness to the need of a more structured approach to the professionalization through arts and culture.

Expected results:

1. Focus groups

Each partner country has implemented 3-4 focus group discussions, in order to discuss crucial topics to be included in the Clap course. Participants of these focus groups were professionals within areas of arts, healthcare, and or had worked with artists with disabilities. The main discussion concerned what type of skills and competencies should the Clap course offer the trainees who work with persons with disabilities in order for them to contribute to their labor inclusion and professionalization through arts and culture.

In conjunction with the focus group discussions, each partner country interviewed 8-10 artists with various types of disabilities in order to gain knowledge and recommendations for institutions and other persons with disabilities who would like to become a professional within arts.

2. Best practice guide

Is a compendium of best practices and success stories of how organizations as well as individual artists create successful strategies to foster the development of art as a profession for persons with disabilities. A compendium to inspire artists and institutions that give them support from other EU members states to include disabled artists in the active population and contribute to enhance the cultural expression of the country with their unique talent.

3. Clap course

4 editions ( 1 x country) with 60 trainees ( 15 x country) of a specialized training module for professionals who supervise persons with disabilities in artistic activities and in the capacity of accompany towards professionalization processes in the crafts and culture, will be built from the contributions obtained by the other project productions.
\end{abstract}

Keywords: Disabled, competencies, training, arts and culture, labor inclusion.

\section{About the project}

The CLAP HANDS “Creative Lab: Access to Profession for persons with Handicap" is a 2 years (2017-2019) project financed by the ERASMUS+ Program, under the key action "Cooperation for Innovation and the Exchange of Good Practices".

\subsection{Consortium}

The project is coordinated by Institut Régional du Travail Social (IRTS) Languedoc, Roussillon- (FR) with three more partners from (FR): ESAT La Bulle Bleue and Passeport Europe, two from (ES): Foro Técnico de Formación and Artistas Diversos, one from (PT): COFAC and one from (SE): STIFTELSEN KURSVERKSAMHETEN VID U-AUNIVERSITET 


\subsection{Context}

Europe has 80 million citizens with disabilities, or 1/6 of the population (source Eurostat). Their employment rate is $50 \%$ ( $72 \%$ for the general population) and their poverty rate $70 \%$ above average, partly because their access to employment is limited. The European goal of HORIZON 2020 to employ $75 \%$ of people aged 20 to 64 cannot be reached if these people are not taken into account. Accessibility and professionalization are among the top priorities of this strategy that targets inclusive strategies and improved access to employment.

As early as 2003, a European declaration set accessibility as the guarantee of integration of people with disabilities into crafts, culture and the media. These sectors are a pool of professional opportunities. Creative practices are many in medico-social settings but often limited to therapeutic, rehabilitative approaches (occupational therapy), or occupational with a weak opening on the "ordinary" social world. Beyond a better affirmation and participation of the person, the creativity opens on the professionalization. Across Europe, there are experiences events, networks or support, for professional purposes, but these initiatives are relayed poorly at the national level, let alone at the European level. On the contrary, it is in these institutions that these educational mediation practices are the most numerous. And, the least inclusive because they have no or few actions directed towards the ordinary environment of life. Concerning professionals (social workers interested in art or artists interested in social work), there is an initial and continuing qualification gap to better support individualized career paths towards these professions.

\subsection{Objectives}

1.3.1. Main objectives. CLAP aims to qualify professionals to contribute to the professional inclusion of people with mental disabilities or psychic:

- To train, to qualify the supervisors of these practices to develop the creativity of the accompanied persons, to sensitize accessible trades and thus move from the occupational to a professionalization dynamic

- To identify and valorize the best practices of professionalization of these publics but also all initiatives to reinforce their access to job and activity trails

- Network, share, and capitalize on the achievements of existing practices and experiences to create access to good practices, identify reluctance and obstacles to this professionalization

- Sensitize the professional world of culture (places, networks, groups ...) but also the public authorities on the professionalization in sectors targeted at good practices and their deployment.

1.3.2. Operational objectives. Initiate a European network of social and medico-social organizations, training institutes or universities involved in professional insertion through art and culture but also professionals from the "ordinary" world of culture and entertainment living

- Collect and promote the best practices in terms of inclusion (ergonomics, accessibility, reception equipment, mediation, existing experiences ...) and to better know and communicate about accessible trades, particularities and types of writing artistic, creative practices...

- Build and validate a training device for professionals (social workers and artists) accompanying / training people with disabilities in creative activities and cultural production.

- Create the required environment based on new technologies and social networks but also on workshops multidisciplinary approaches to support the action research process - Identify the criteria for pre-professionalization, professionalization and conditions of access to the trades

- Animate the system by involving all stakeholders (including local authorities in their cultural competence) to anchor this collaborative culture and define the criteria for modeling and transferability transnational approach

\section{Expected results}

\subsection{Focus groups}

2.1.1. Implementation of Focus groups and artist interviews. During the period of spring 2018 - winter 2019, each partner country implemented 3-4 focus group discussions, in order to discuss crucial topics to be included in the Clap course.

Participants of these focus groups were professionals within areas of arts, healthcare, and or had worked with artists with disabilities. Further, each partner country discussed within the focus groups, the state of the art of existing supports, activities, possibilities and institutions welcoming artists with 
disabilities in respective country, and what improvements needs to take place regarding respective area. The main discussion concerned what type of skills and competencies should the Clap course offer the trainees in order for them to contribute to the labor inclusion and professionalization of persons with disabilities in the field of arts and culture.

In order to gain knowledge about possible existing barriers (internal as well as external) on the way to get to where they are today, each partner country interviewed 8-10 artists with various types of disabilities. The interview touched the subjects of inclusion in the arts as of perceived by the artists, and recommendations for institutions and other persons with disabilities who would like to become a professional within arts.

2.1.2. Recommendations and improvements after the focus groups. Professional cultural workers who want to work with people with disabilities should present their pedagogical attitude rather than their own artistry. Inclusive education and healthy approaches are the smallest common denominator for education.

- Knowledge acquisition and development

- Pedagogy and the ability to make others grow in their knowledge.

- Adaption in working method, communication. For example, artistic teams: learning adaptions for theater rehearsals: recording the manuscript so the actor can learn while listening instead of reading.

- Access to mainstream integration devices such as identification of skills and implementation in professional situation (in France this is one of the roles of "Pôle emploi or Cap Emploi") It is only partially open to disabled people in protected areas... Simplifications must be done to these separations.

- Professionals who can liaise the artistic aspects and the aspects of psycho-social support are needed. In order to support a professional project and a life project in knowledge of the existing actions on the territory. Moreover, with a good knowledge of devices to support the path of people with disabilities.

- They need to be attentive to the great diversity of disability situations. Although major concerns are common (including the dimensions of recognition), the questions do not arise in the same way depending on the disability: motor, sensory, cognitive deficiency, psychic disability...

\subsection{Best practice guide}

2.2.1. Objectives. Understanding of the local and European environment of disabled community in general and of artists in particular.

- Health support: analyse existing sanitary services to improve quality of life of this community.

- Basic therapeutically art training, and detection of talent in order to give professional training,

- Mentoring support from different agents: administration, local organization, art centers, galleries and well-known artists, etc.

- Sanitary system - tools and services to care for the health of the community with disability in Europe

- Mechanism for social inclusion - personal environment, social and political organizations

- Barriers that artists have to develop professionally - in each country of the partnership. For example: action on Change.org to make the barrier and exclusion visible and collect signatures to try to eliminate these barriers. Other initiatives the Partners may suggest.

- Working activities - different types of tasks that artists can do in different types of companies. Identifying different ways to develop independent labor and professional life.

2.2.2. Methodology. A European opinion research oriented to collect relevant information from the different countries on the issues focused by the project.

- Desk research- to collect as much information and best practices from as many countries as possible in order to share strategies that can benefit all parties.

- Set up a panel - of associations and institutions in the four countries of the partnership. Partners will invite organizations from other European member states in order to broad the scope of information.

- WAVES -four waves of sets of questions are sending to the panellists to collect their information, opinion and suggestion for each of the areas research by the project.

- Interviews - with agents in the different countries, as well as with artists to collect personal experience.

Six phases of research:

1. Desk research of the art and disability environment in the European Union and set up project panel

2. Support for this community: public and private sanitary services, legal, mentoring, other 
3. Education and training: public and private training facilities to foster the development of art as a profession

4. Professional career: fields in which artists with disability can enter the work market and develop personally and professionally

5. Barrier: barriers and difficulties persons with disability may face in entering the work market in order to propose solutions to avoid discrimination and foster inclusion

6. Report: Final report and compendium that features the quality process toward art as a profession

\subsubsection{Final report content}

- Compendium of 4 Wave Reports

- $\quad$ Cases and best practices sent by panelists

- Interview made by all partners during the collection of information for the GUIDE to broaden information.

- Suggestions to improve quality of support and to prevent discrimination and foster inclusion of persons with disability in the artistic fields and professions

\section{Clap course: Technicians of labor inclusion of people with disabilities in artistic and} cultural environments (April-May 2019)

\subsection{Introduction}

Specialized training module of 20 hours, in face to face modality, for professionals who supervise persons with disabilities in artistic activities and in the capacity of accompany towards professionalization processes in the crafts and culture, will be built from the contributions obtained by the Best Practice Guide and by the Focus Groups recommendations, for the following professionals:

- $\quad$ Specialists in initial training

- Social workers in continuing education

- $\quad$ Professionals/coach / supervisor of people with disabilities

- $\quad$ Associated artistic teams

- Trainers supervising activities training in the training of social workers

- Trainers (from the sector of protected work, art and culture)

- Managers

- $\quad$ Responsible for the animation of the disability sector

- Coordinators of artistic production and supervisor health and social care.

- Professional Artist

This training can be applied both in the initial training by integrating as an option in the regulatory programs (with an equivalent of ECVET) as in continuing education (skills approach)

\subsection{Selection of participants}

Will be 12/15 learners per country. Total 60

The method of selecting the participants will be (not exclusive)

1) By coincidence with the specified target group.

2) By origin: Professionals of the partners, professionals of the organizations that have participated in the rest of the intellectual products of the project, in the $\mathrm{O} 2$ interviews in the O3's workshops or professionals from other organizations

3) By order of request

We made a promotion through the desired channels, mail chimp, social networks, and partner's web site.

An informative PowerPoint presentation will be prepared for it.

\subsection{Selection and preparation trainers}

Not more than two or three per course.

They must be expert in labor inclusion of people with disabilities and/or in artistic and cultural environments, with experience in professional training and with experience in e-learning tutoring.

They must collaborate in the course resources, especially in the face-to-face session's documents (Power point presentations, etc...)

They must have already been selected (Nov-Dec 2018) from the technical team of partners or can be hired between collaborators, in each country, with part-time contracts.

We will be training them in our project issues, objectives, activities and products, and especially in our evaluation, plan and tools related to the $\mathrm{O} 4$ course, competencies evaluation mainly objectives

This training will be dividing into 3 main areas knowledge: Relating to social competencies, to the skills of the artistic professions and to the specificity of people with disabilities knowing that these situations are very diverse and therefore require very diverse responses. 
Two types of training modules can be defining: Elements of prerequisites (technical competencies) for social workers in initial training and more advanced content for social workers in post by mixing with the public artists interested in social work.

\subsection{Competencies and contents}

Table 1. Competencies and moduls.

\begin{tabular}{|c|c|c|}
\hline \multicolumn{3}{|c|}{ TECHNICAL AND SECTOR COMPETENCIES } \\
\hline UNIT OF COMPETENCY & \multicolumn{2}{|r|}{ MODULS } \\
\hline \multirow{2}{*}{$\begin{array}{l}\text { 1. Information management, } \\
\text { evaluation and guidance } \\
\text { for training and } \\
\text { employment }\end{array}$} & \multicolumn{2}{|c|}{$\begin{array}{l}\text { 1. Updated location of available socio-labor and training resources, including } \\
\text { possibilities for work practices }\end{array}$} \\
\hline & \multicolumn{2}{|c|}{ 2.Cultural and artistic activities } \\
\hline \multirow[t]{2}{*}{ 2. Support for qualification } & \multicolumn{2}{|c|}{$\begin{array}{l}\text { 3.Selection of the necessary training, registration and monitoring of the } \\
\text { acquisition of skills and qualifications }\end{array}$} \\
\hline & \multicolumn{2}{|c|}{ 2.Cultural and artistic activities } \\
\hline \multirow{2}{*}{$\begin{array}{l}\text { 3. Support for Integration, } \\
\text { Maintenance and } \\
\text { Reintegration in the Labor } \\
\text { Market }\end{array}$} & \multicolumn{2}{|c|}{$\begin{array}{l}\text { 4.Promotion of the insertion of people with disabilities and disabilities in the labor } \\
\text { market }\end{array}$} \\
\hline & \multicolumn{2}{|c|}{ 2.Cultural and artistic activities } \\
\hline \multirow{2}{*}{ 4. Post-placement support } & \multicolumn{2}{|c|}{ 5.Information, evaluation and guidance for qualification and employment } \\
\hline & \multicolumn{2}{|c|}{ 2.Cultural and artistic activities } \\
\hline \multicolumn{3}{|c|}{ SOCIAL COMPETENCIES } \\
\hline \multicolumn{2}{|c|}{ UNIT OF COMPETENCY } & MODULS \\
\hline \multicolumn{2}{|c|}{$\begin{array}{l}\text { 5. Support singularity, capacity, personality and } \\
\text { potential }\end{array}$} & \multirow{5}{*}{$\begin{array}{l}\text { 6.Performance focused on people first, according to their } \\
\text { needs in terms of ability }\end{array}$} \\
\hline \multicolumn{2}{|c|}{$\begin{array}{l}\text { 6. Get to know people through evaluation / } \\
\text { discovery }\end{array}$} & \\
\hline \multicolumn{2}{|c|}{ 7. Promote the right as an integral part of the person } & \\
\hline \multicolumn{2}{|c|}{ 8. $\quad$ Facilitate personal growth and development } & \\
\hline \multicolumn{2}{|c|}{ 9. $\quad$ Develop professional relationships } & \\
\hline \multicolumn{2}{|c|}{ 10. Exhibit professional behavior } & \multirow[b]{2}{*}{ 7. Demonstrate professionalism } \\
\hline \multicolumn{2}{|c|}{$\begin{array}{l}\text { 11. Activities of Education, Training and self- } \\
\text { development }\end{array}$} & \\
\hline \multicolumn{2}{|c|}{$\begin{array}{l}\text { 12. Give active support to participation in this } \\
\text { community }\end{array}$} & \multirow{2}{*}{ 8.Be active and productive in the Society } \\
\hline \multicolumn{2}{|c|}{$\begin{array}{l}\text { 13. Support employment, education and professional } \\
\text { aspiration }\end{array}$} & \\
\hline
\end{tabular}

\subsection{Evaluation and certification tools}

- Participants (trainees) expectation questionnaire.

- Participants (trainees and trainers) satisfaction questionnaire

- Competencies evaluation by trainer at the start and at the end of course

Responsible: In every country the partner member of evaluation team

To obtain the Declaration of Attendance the student must attend the $75 \%$ of face-to-face sessions

\section{References}

European Commission, Erasmus+ Project Results Platform. ("n.d."). Creative Lab : Access to Profession for Persons with Handicap June, $4^{\text {th }} 2019$ from https://ec.europa.eu/programmes/erasmusplus/projects/eplus-project-details/\#project/980d58fd-4cf3-427c-a59c-64f92bb44ee9

Project Consortium, CLAP HANDS access to profession for persons with handicap (June 2018) Best Practices Guide, June $4^{\text {th }} 2019$ from http://www.claphands.eu/wp-content/uploads/best-practiceguide.pdf

Project Consortium, CLAP HANDS access to profession for persons with handicap (November 2018) Pedagogical Guide, June $4^{\text {th }} 2019$ from http://www.claphands.eu/wp-content/uploads/clappedagogical-guide_v2.pdf 